\title{
COMMENTARY
}

\section{Promoting Early Detection of Breast Cancer and Care Strategies for Nigeria}

\author{
Agatha Ogunkorode $^{1 *}$, Lorraine Holtslander ${ }^{1,2}$, June Anonson $^{1,}$ and Johanna Maree ${ }^{3}$ \\ Graduate Student, College of Nursing, University of Saskatchewan, 104 Clinic Place, Saskatoon, SK S7N2Z4, \\ Canada $^{1}$; University of Witwatersrand, South Africa ${ }^{2}$; Department Nursing Education, University of Witwatersrand, \\ South Africa ${ }^{3}$
}

*For Correspondence: Email: aolufunke@gmail.com; aoo121@mail.usask.ca; Phone: +16399980727

\begin{abstract}
Breast cancer is the most common cancer in women particularly in developing countries like Nigeria, with high mortality, and economic costs. Worldwide, it is predicted that more than one million women are diagnosed with breast cancer, and more than 400,000 will die from the disease every year. A comparative integrative review of the literature from Nigeria and Canada showed that in Canada, there is positive association between wide spread education, early detection, the disease stage at diagnosis, and survival rates. In Nigeria, presentation with the advanced stage of the disease makes survival very low. The primary factors responsible for the late presentations are lack of awareness, misconceptions about breast cancer causes, and treatment outcomes. It is recommended that guidelines and policies about breast cancer early detection, care strategies, and ongoing management pathways be produced, disseminated, and adopted. The guidelines will assist practitioners and patients in making informed decisions and choices about the most appropriate health care for their specific clinical situations. The implementation of evidence-based guidelines will most likely help to improve care processes, the quality of clinical decisions and patient treatment outcome. (Afr J Reprod Health 2017; 21 [2]: 18-25).
\end{abstract}

Keywords: Breast cancer, awareness, early detection of cancer, cancer care, Nigeria, Canada

\section{Résumé}

Le cancer du sein est le cancer le plus commun chez les femmes, surtout dans les pays en développement comme le Nigeria, avec une mortalité élevée et des coûts économiques. Dans le monde entier, on prévoit que plus d'un million de femmes sont diagnostiquées avec un cancer du sein et plus de 400000 mourront de la maladie chaque année. Un examen comparatif des documents venant du Nigéria et du Canada ont montré qu'au Canada, il existe une association positive entre l'éducation largement répandue, le dépistage précoce, le stade de la maladie au moment du diagnostic et les taux de survie. Au Nigéria, la présentation au stade avancé de la maladie rend la survie très faible. Les principaux facteurs responsables des présentations tardives sont le manque de sensibilisation, les idées fausses sur les causes du cancer du sein et les résultats du traitement. Il est recommandé de produire, de diffuser et d'adopter des lignes directrices et des politiques sur la détection précoce du cancer du sein, les stratégies de soins et les parcours de gestion en cours. Les lignes directrices aideront les praticiens et les patients à prendre des décisions et des choix éclairés sur les soins de santé les plus appropriés pour leurs situations cliniques spécifiques. La mise en œuvre de lignes directrices fondées sur des données probantes contribuera vraisemblablement à améliorer les processus de soins, la qualité des décisions cliniques et les résultats du traitement de la patiente. (Afr J Reprod Health 2017; 21 [2]: 18-25).

Mots clés: Cancer du sein, sensibilisation, dépistage précoce du cancer, soins contre le cancer, Nigeria, Canada

\section{Introduction}

Globally, breast cancer is the most common malignancy particularly in women; its incidence having increased by over $20 \%$ and breast cancerrelated deaths by $14 \%$ since $2008^{1}$. The stage of the disease at diagnosis has a great influence on determining the outcome of the illness ${ }^{2,3}$. Breast cancer has been recognized as an urgent public health problem in high-resource regions of the world. The cancer burden in low-middle-income countries is growing, with the survival rates much poorer than those in high-income countries ${ }^{4,5}$. In low-middle-income countries like Nigeria, advanced stage of the disease at diagnosis and delayed treatment represent notable problems ${ }^{6-9}$. Compounding the problem of late stage diagnosis of breast cancer in developing countries are lack of 
healthcare infrastructure and resources necessary to implement early detection, diagnosis and treatment of breast cancer. Therefore, breast cancer is becoming an increasingly urgent problem in low-resource regions ${ }^{10}$.

It has been predicted that breast cancer burden in low to middle-income countries will continue to increase in coming years as a result of increasing life expectancy ${ }^{10-12}$. It has also been predicted that between 2002 and 2020, there could be a nearly $50 \%$ increase in global incidence due to demographic changes alone ${ }^{13}$. These increases will be disproportionately high in the developing world, with projected respective increases of $55 \%$ and $58 \%$ in incidence and mortality by 2020 when compared to the known statistics ${ }^{13,14}$. These statistics may most likely underestimate the actual increasing breast cancer rates because the few data available reveal increases in breast cancer agespecific incidence and mortality rates ${ }^{15}$. This increase in incidence probably will be caused at least in part by the adoption of Western lifestyles ${ }^{12}$. Previous study also indicates that the incidence of breast cancer in Nigeria is increasing ${ }^{15}$.

An integrative review recently conducted identified some challenges in breast cancer early detection, diagnosis, and care in Nigeria ${ }^{16}$. Some of those challenges include lack of knowledge and awareness about breast cancer and breast health issues, inadequate infrastructure, the influence of cultural beliefs, poverty, and various misconceptions about breast cancer and its treatment outcomes. Fear of deformity and loss of a body part such as in the case of mastectomy are some of the concerns that women with breast cancer face ${ }^{17}$. There is distrust of the medical system, leading breast cancer patients to rely on traditional and spiritual healers instead of orthodox health centers ${ }^{18}$. Obstacles to improving breast cancer care arise from multiple sources, including a deficit in public knowledge and awareness about breast cancer, social and cultural barriers. As noted earlier, as a result of demographic changes and lack of access to early diagnosis and treatment in a developing country like Nigeria, there is the likelihood of increases in the incidence of and mortality from breast cancer ${ }^{12}$. In countries with limited resources, widespread introduction of culturally sensitive, linguistically appropriate, local education programs to teach breast health awareness is critical ${ }^{19}$. Such training activities should initially target healthcare providers, trusted traditional leaders, governmental agencies, and the general public about breast health, early detection, diagnosis, and treatment of breast cancer ${ }^{20}$.

To successfully implement breast cancer control strategies globally, three goals must be addressed: a) the development and dissemination of treatment guidelines with implementation plans, b) education of healthcare providers and health system administrators for guideline adoption to be successfully sustained, and c) making available effective and affordable technology so that early detection, diagnosis, and treatment of breast cancer can be performed ${ }^{21-23}$. Addressing these goals are important because, introduction of wide spread education, early diagnosis, and treatment have been shown to improve survival rates of patients with breast cancer in Canadian provinces ${ }^{24}$.

\section{The importance of early detection and diagnosis of breast cancer}

Early detection has been described as screening and identification of asymptomatic disease with mammographic screening and identification of symptomatic disease through self-breast examination and clinical-breast examination ${ }^{10,25}$. Early detection of breast cancer takes into account factors such as tumor size and whether the illness has spread to the regional lymph nodes ${ }^{3}$. The primary objective of early detection or secondary prevention through screening is to detect early stage cancers ${ }^{26}$. The goal of earlier detection in low-resource regions is to treat the disease on time so as to prevent it from spreading. This goal can be achieved by reinforcing the importance of seeking timely examinations and treatments ${ }^{26-30}$. Diagnosis of breast cancer in the earlier stages of the disease has been positively associated with a decrease in breast cancer mortality and improved prognosis ${ }^{10}$. Detection in the earlier phase of breast cancer can also provide comfort to those who receive a timely diagnosis early in the disease pathway ${ }^{10,3}$. Although mammography screening is the most widely used tool for diagnosing breast cancer early, this screening method is not a plausible solution in every country, in the light of socioeconomic constraints ${ }^{10,26,27}$. However, it is 
important that there exists a symptomatic care pathway in every healthcare system to detect breast cancer early, prevent metastasis, and deliver adequate treatment services ${ }^{3,27}$.

\section{Breast health global initiative (BHGI) treatment guidelines}

Evidence-based guidelines, delineating best approaches to breast cancer early detection, diagnosis, and treatment have been well developed and distributed in several high-resource countries ${ }^{28-}$ ${ }^{30}$. These guidelines have limited utility in low-tomiddle income countries because they outlined optimal and best principles. These best principles may be inappropriate for various reasons, including a shortage of appropriate and adequate human resources, limited health care infrastructure, lack of pharmaceuticals, and cultural barriers ${ }^{30-32}$. Therefore, there is a need to develop clinical practice guidelines specifically tailored to lowmiddle income countries. The existing health care resources in these settings need to be taken into consideration while producing such guidelines ${ }^{10}$.

The Breast Health Global Initiative (BHGI), cosponsored by the Fred Hutchinson Cancer Research Center and Susan G Komen for the Cure of Breast Cancer, encouraged the development of evidence-based, economically feasible, and culturally sensitive guidelines that can be used in nations with limited health care resources, with the aim of improving breast cancer

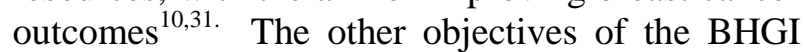
guidelines are to assist ministers of health, policymakers, administrators, and institutions in working out resource allocation as breast cancer treatment programs are implemented in their resource-constrained regions ${ }^{3,31}$. The central notion on which the BHGI was founded was that not every patient with breast cancer can receive the maximal level of care in countries with limited resources $^{10,31}$. Most existing treatment guidelines are not applicable in countries with limited resources because many diagnostic or therapeutic interventions are simply not available ${ }^{32}$. The World Health Organization (WHO), therefore, directed that the priority, particularly in developing countries, should be to develop national diagnostic and treatment guidelines or principles that establish a minimum standard of care and to promote the rational use of existing resources while at the same time promoting equity in access to treatment ${ }^{33}$. Consistent with this statement, the objective of the BHGI was aimed at defining reasonable priorities that ensure evidence-based and equitable use of available resources ${ }^{10,26,33}$, including the need for palliative and supportive care within existing health care systems ${ }^{33}$. It has been recommended, therefore, that developing countries should be encouraged to develop palliative and supportive care for patients with advanced breast cancer because, at this stage, patients will no longer gain from antitumor interventions ${ }^{10}$. The creation of palliative and supportive care for patients with advanced breast cancer will help to prevent unnecessary and avoidable suffering.

\section{Palliative and supportive care}

Palliative care has been defined as an approach that improves the quality of life of patients living with life-threatening illness, through assessment and treatment of pain, suffering, physical, psychological, spiritual, and other problems ${ }^{34}$. Palliative care in breast cancer is usually prolonged because patients with metastatic breast cancer can now survive longer because of advances in technology and available treatment options ${ }^{35}$. Without good palliative care, the implications of long survival rates are prolonged suffering ${ }^{3,35}$. Although palliative care is now a human right, it is scarce in low-middle income countries ${ }^{3,10,35}$. In many low-middle income countries, it is the religious bodies and non-governmental organizations that usually start palliative care services. In Nigeria, palliative care is a relegated aspect of medical practice ${ }^{36}$. However, recommendation has been made of the importance of incorporating palliative care services into the national health services ${ }^{10,33,35}$.

The WHO considers a country's annual consumption of morphine to be an indicator of access to opioids for the treatment of pain. In 2008, low-middle income countries accounted for 9\% while high-income countries accounted for $83 \%$ of the world's consumption ${ }^{37}$. There is, therefore, a need for appropriate policies for drug availability, physician and patient education with the objective of ensuring adequate access to pain control and improving the quality of end-of-life care ${ }^{37}$. 


\section{Policy developments for Nigeria}

The World Health Assembly Resolution on Cancer Prevention and Control in May 2005 called on member states to intensify action against cancer by developing cancer strategies ${ }^{38}$. Breast Health Global Initiative developed resource specific and evidence-based guidelines for aspects of breast cancer management ${ }^{26,31}$. Since Nigeria is not exempt from the burden of breast cancer, it is important that all interested stakeholders unite and work towards a common goal that is the reduction of breast cancer and breast cancer-related mortality in the Nigerian population. Therefore, it is imperative that a national policy on breast cancer be developed to address this illness in a coordinated way. This system should adopt a multidisciplinary approach which will likely lead to best results ${ }^{3}$.

In high-resource countries, evidence-based guidelines mapping out best approaches to the early detection, diagnosis, and treatment of breast cancer have been defined, developed and distributed $^{35}$. These guidelines are resource neutra $^{30}$. They fail to consider variable resources distribution where overall standards of living are high, and they also fail to recognize pervasive deficits in infrastructure and resources in low to middle-income countries ${ }^{30}$. They neither consider implementation costs nor provide guidance on how a suboptimal system can be improved gradually towards an optimal system ${ }^{10}$. Such principles defining best breast cancer care and services, as pointed out by WHO (2005), have limited use in resource-limited countries ${ }^{36-38}$. It is therefore, important to produce resource-based guidelines and policies for breast cancer care $e^{10,37,38}$.

To improve breast health and breast cancer care, it is critical to develop, disseminate, and implement evidence-based, resource-capacity specific breast healthcare principles tailored to countries or regions of the world with limited financial resources ${ }^{10}$. Although healthcare strategies may differ appreciably, improvement in breast cancer outcomes can be achieved by using the best standard of care that is practical and feasible in a given situation ${ }^{10}$.

The World Health Organization resolution on cancer prevention and control ${ }^{38}$, at the 58th
World Health Assembly in 2005, encouraged member states to collaborate with the WHO in the development of cancer control programs aimed at reducing cancer mortality and improving the quality of life of cancer patients and their families ${ }^{38}$. This resolution calls on low-middleincome countries to: a) incorporate cancer control programs within the existing health systems, b) identify evidence-based, sustainable actions across the continuum of cancer care, and c) make the best use of available resources to benefit their populations afflicted with cancer. Low-middleincome countries are also encouraged to: a) support research translating knowledge into effective public health measures for cancer prevention and treatment, b) improve access to appropriate technologies for the early diagnosis and treatment of cancer, and c) promote research involving low-cost interventions that are affordable and sustainable ${ }^{10,39}$. In alignment with WHO (2005) recommendations and the findings of an integrative review of the literature comparing research from Canada, a developed country, and Nigeria a developing $\operatorname{country}^{16}$, the following recommendations are proposed for Nigeria.

\section{Policy guideline recommendations for Nigeria}

Nigeria could benefit from the establishment of clinical practice guidelines for screening, treatment, and palliative care as well as breast health education, and research centers. It is essential to make available clinical guidelines outlining a symptomatic care pathway that provides a clear point of contact for patients, followed by a timely diagnosis and treatment. Outlining a clear care pathway for breast cancer care for patients will most likely result in better treatment outcome. A better treatment outcome can help to debunk some misconceptions about breast cancer treatment outcomes. The guidelines should however, emphasize the importance of recognizing symptoms early, and seeking appropriate interventions.

They should include:

i. The development, dissemination, and implementation of community breast health awareness education programs that promote the practice of breast self-examination. 


\section{Ogunkorode et al}

ii. Modalities for the detection and treatment of early stage breast cancer thereby improving treatment outcome ${ }^{33}$.

iii. Establishment of centralized breast cancer care centers with sufficient infrastructural facilities and a multidisciplinary team of care providers thus avoiding the fragmentation of care ${ }^{39}$. Barriers to facility utilization need to be identified and addressed.

iv. The training of healthcare providers such as nurses, midwives, and community extension workers on breast self-examination and clinical breast-examination which will significantly improve breast cancer treatment outcome.

v. The establishment of a comprehensive national health insurance policy and special funds for the treatment of breast cancer. The availability of special funds for the treatment of breast cancer have the potential of encouraging individuals living with the disease to get timely and appropriate medical care ${ }^{40}$.

vi. Adequate budgetary allocation should be provided for issues related to breast cancer care in Nigeria.

vii. Palliative care will necessarily have to be incorporated and integrated into existing health care services ${ }^{35,39,41}$.

viii.Making available appropriate modalities for the procurement of drugs. Appropriate guidelines for drug availability, which will ensure adequate access to pain control medications will prevent unnecessary and preventable suffering of the patients. It might also contribute to improving the quality of endof-life care of the patients ${ }^{35,37}$.

ix. Rehabilitation programs and support groups for breast cancer survivors need to be encouraged and supported.

$\mathrm{x}$. The incorporation of the traditional and alternative health care institutions into a comprehensive breast cancer healthcare plan.

xi. Strengthening of existing cancer registries and the establishment of more viable ones to provide vital information about breast cancer in Nigeria. This will enable proper allocation of resources to meet actual needs.

xii. Socio-cultural barriers and misconceptions that negate the early detection and treatment of breast cancer need to be identified and tackled.
Breast Cancer Early Detection and Care

Thus, studies that seek to understand the barriers and misconceptions related to breast cancer should be supported.

xiii.Quality assurance strategies should be incorporated into the policy guidelines to prevent unnecessary duplication of programs.

xiv. Networking with other low-middle and highincome countries about breast cancer care best practices and available resources will help to address the burden of breast cancer in the Nigerian population.

\section{Conclusion}

There is little doubt that because of demographic changes and lack of access to breast cancer early diagnosis and treatment in a developing country like Nigeria, there may be a continuous increase in the incidence of and mortality from breast cancer. It is crucial that there be a widespread increase in educational programs to increase awareness and encourage early detection and presentation of breast cancer. Such education programs should be culturally sensitive and linguistically appropriate. Nigeria like many other low-income countries faces many challenges. Socio-cultural barriers to seeking early detection and treatment continue to exist. Early detection programs need to continue to address socio-cultural barriers to seeking timely medical care and participation in breast health activities. Nigeria should also address health system and health financing barriers. Health system barriers identified in Nigeria include lack of adequate infrastructure, limited access to breast care, delay in diagnosis and treatment, and a lack of palliative care services, all of which depend on the efficiency of the health services available.

Coordinated screening programs, cooperative drug acquisition strategies, quality assurance, and in-country accreditation and training programs should be developed cooperatively with universities, health ministries, and community advocates. Low-middle-income countries share similar economic challenges in the area of breast cancer control. Sharing examples of successful efforts to improve care through research, consensus reviews, building networks, and collaborations will continue to contribute to improving breast cancer care and outcome. 
Concerted efforts and actions, led by the global health community, together with the participation of local governments, extensive primary healthcare networks including non-governmental organizations, civil service organizations, religious bodies, and traditional and alternative healthcare providers will significantly improve breast cancer treatment outcomes in a low-middle income country like Nigeria.

\section{Declaration}

All the authors declare that they have no competing interests.

This manuscript has not been submitted for publication and it is not being considered for publication elsewhere.

\section{Contribution of Authors}

A. Ogunkorode. The current study is part of the outcome of A. Ogunkorode's Master of Nursing thesis. She made a substantial contribution to the conception, design, data collection, data analysis, and interpretation of the findings. Also made substantial contribution to the drafting, writing, editing, and correction of the manuscript. She is the corresponding author. She read and approved the final version for publication.

L. Holtslander made substantial contribution to the conception of the study. She also contributed to the design, collection of data, data analysis, and interpretation of findings. She made contribution to the drafting of the article, revising it critically, and making sure that it contained important intellectual content. She contributed to the editing, reading, and approval of the final version to be published.

J. Anonson made substantial contribution to the conception, design, and interpretation of the findings. She made important editing, revising manuscript critically making sure that it contained important intellectual content. She read and approved the final version to be published.

M. Johanna made important and substantial contributions to the conception, design and interpretation of findings. She contributed to the drafting, reading, and editing of the article. She made important intellectual contributions to the article. She read and approved the final version to be published.

\section{Acknowledgement}

This paper is part of the outcome of the first author's Master of Nursing thesis. There was no external funding from any source.

\section{References}

1. GLOBOCAN. Cancer incidence, mortality, and prevalence worldwide. International Agency for Research on Cancer (IARC 2012-2014).

2. Jemal A, Center MM, DeSantis C, and Ward ED. Global patterns of cancer incidence and mortality rates and trends. Cancer Epidemiology. Biomarkers Prevention 2011; 19, 1893-1907.

3. Yip CH and Taib A. Challenges in the management of breast cancer in low-and middle -income countries. Future Oncology 2012; 8(12), 1575.

4. Farmer P, Frenk J, Knaul FM, Shulman LN, Alleyne G, Armstrong L, Awn R, Blayney D, Chen L, Feachen R, Gospodarowicz M, Gralow J, Gupta S, Langer A, Lob-Levyt J, Neal C, Mbewu A, Mired D, Piot P, Reddy KS, Sachs JD, Sarhan M and Seffrin, JR. Expansion of cancer care and control in countries of low and middle income: A call to action. The Lancet 2010; 376(9747), 1186-1193. doi:10.1016/S01406736(10)61152-X

5. Jenson OM, Parkin DM, MacLenna R, Muir CS and Skeet RG. Cancer registration: Principles and methods. IARC Scientific Publications No. 95. Lyon, France. International Agency for Research on Cancer 1991.

6. Oluwatosin OA and Oladapo O. Knowledge of breast cancer and its early detection measures among rural women in Akinyele Local Government Area of Ibadan, Nigeria. BMC Cancer 2006; 6, 271. Retrieved from http:/www.biomedcentral.com/14712407/6/271

7. Oluwatosin OA. Assessment of women's risk factors for breast cancer and predictors of the practice of breast self-examination in two rural areas near Ibadan, Nigeria. Cancer Epidemiology 2010; 34, 425-428. doi:10.1016/j.canep.2010.04.005

8. Pruitt L, Mumuni T, Raikhel E, Ademola A, Ogundiran T, Adenipekun A, Morhason-Bellow I, Ojengbede OA and Olapade OI. Social barriers to diagnosis and treatment of breast cancer in patients presenting at a teaching hospital in Ibadan, Nigeria. Global Public Health: An International Journal of Research, Policy and Practice 2015; 10(3), 331-344.

9. Richards L. Defining a global research agenda for breast cancer. Cancer 1999; 113, 2366-2371.

10. Anderson BO, Yip CH, Smith RA, Roman S, Sener SF, Eniu A, Carlson RW, Azavedo E and Harford J. 
Ogunkorode et al

Guideline implementation for breast healthcare in low-income and middle-income countries: Overview of breast the Breast Health Global Initiative Global Summit 2007. Cancer 2008; 113(Supplement), 2221-2243

11. Ferlay J, Shin HR, Bray F, Forman D, Mathers C and Parlin DM. Estimates of worldwide burden of cancer in 2008: GLOBOCAN 2008. International Journal of Cancer 2008; 136(5), 359-386. doi:10,1002/ijc. 29210

12. Porter P. " Westernizing" women's risks? Breast cancer in lower -income countries. New England Journal of Medicine 2008; 358, 213-216.

13. Parkin D and Fernandez L. Use of statistics to access the global burden of breast cancer. Breast Journal, 12(Suppl.1), S81-90. Cancer 2006; 113(8), 22212243.

14. Anderson BO, Shyyan R and Eniu A. Breast cancer in limited-resource countries: An overview of the Breast Health Global Initiative guidelines. Breast Journal 2005; 12(1), S3-S15.

15. Jedy-Agba E, Curado MP, Ogunbiyi O, Oga E, Fabowale $\mathrm{T}$, Igbinoba $\mathrm{F}$ and Adebamowo $\mathrm{C}$ A. Cancer incidence in Nigeria: A report from populationbased cancer registries. Cancer Epidemiology 2012; 36(5), e271-e278. doi: http://dx.doi.org/10.1016/j.canep.2012.04.007.

16. Ogunkorode A, Holtslander L, Anonson J and Maree J. An integrative review of the literature on the determinants of health outcomes of women living with breast cancer in Canada and Nigeria from 1990 to 2014: A comparative study. International Journal of Africa Nursing Sciences (2017), 6, 52-73. doi:http://doi.org/10.1016/j.ijans.2017.04.002.

17. Ajekigbe AT. Fear of mastectomy: The most common factor responsible for the late presentation of carcinoma of the breast in Nigeria. Clinical Oncology Research 1991; 3(2), 78- 80.

18. Ibrahim NA and Oludara MA. Socio-demographic factors and reasons associated with delays in breast cancer presentation: A study in Nigerian women. Breast 2012; 21(3), 416-418.

19. Yip CH, Smith RA, Anderson BO, Miller AB, Thomas DB, Ang ES, Caffarella RS, Corbex $M$ and McTiernan DB. Guideline implementation for breast healthcare in low and middle-income countries: Early detection resources allocation. Cancer 2008; 113(8), 2244-2256.

20. Ozmen V and Anderson BO. The challenge of breast cancer in low-middle-income countries: Implementing the breast health global initiative guidelines global summit. BMC Cancer 2008; 6, 271. Retrieved from http:/www.biomedcentral.com/1471-2407/6/271.

21. Anderson BO. Breast cancer-thinking globally. Science 2014; 343, 6178.

22. Sloan FA and Gelband H. Cancer control opportunities in low-and middle-income countries 2007. Washington, DC: National Academies Press.

23. Shulman LN, Willet W, Sievers A and Knaul FM. Breast

\section{Breast Cancer Early Detection and Care}

cancer in developing countries. Opportunities for improved survival. Journal of Oncology 2010; doi: $10.1155 / 2010 / 595167$.

24. Ragaz J and Wong H. Comparative analysis of breast cancer $(\mathrm{BrCa})$ mortality reduction among regions of Canada between 1950-2004: Impact of systemic and diagnostic guidelines after 1977 with model definition of a number of potentially avoided annual deaths (N-PAAD). Cancer 2009; 69(24), 2063.

25. Yip CH, Buccimazza I, Hartman M, Deo SVS and Cheung PSY. Improving outcomes in breast cancer for low and middle income countries. World Journal of Surgery $2011 ; 39,686-692$.

26. Breast Health Global Initiative.The Global submit on International Breast Health: Optimizing healthcare delivery. Seattle, WA. Retrieved from http://portal.bhgi.org/

GlobalPortfolio/globalsummit/pages/Program.aspx: 2010.

27. World Health Organization. Guide for effective programs: Cancer control: Knowledge into action: Module 3: Early Detection. Retrieved from http://www.who.int/cancer/modules/en/index.html:2 007.

28. Yip C, Cazep E, Anderson BO, Bright KL, Caleffi M, Cardoso F, Elzawawy AM, Masood S, Murillo R, Muse IM and Khaled HM. Breast cancer management in middle-resource countries ( MRCs): A consensus statement from the Breast Health Global Initiative. The Breast 2011; 20, S12-S19.

29. Mitra I. Screening for breast cancer: Is it globally applicable? National Clinical Practice of Oncology 2008; 5(2), 60-61.

30. Yip CH, Smith RA, Anderson BO, Miller AB, Thomas DB, Ang E, Caffarella RS, Corbex $M$ and McTiernan A. Guideline implementation for breast cancer in low-income and middle-income countries: Overview of the Breast Health Global Initiative Global summit 2007. Cancer 2008; 113(8), 22212243.

31. Anderson BO. The breast health global initiative: Why it matters to all of us. Oncology 2010; 30(24), 12301238.

32. Durosimi M. Cancer control in an economically disadvantaged setting: Nigeria, an article in Rodrigues, B. (eds). The International Network for Cancer Treatment and Research. Summer, 2004 in African Organization for Research and Training in Cancer (AORTIC) NEWS: The Pulse of Africa 2006; 7, 25.

33. World Health Organization. Screening for Breast Cancer. WHO. Retrieved from http://www.who.int/cancer/detection/breastcancer/en 12008

34. World Health Organization. Definition of palliative care. Retreave from www.who.int/cancer/palliative/definition/en/

35. Eniu A, Carlson RW, El-Saghir NS, Bines J, Bese NS and Vorobiof D. Guideline implementation for breast healthcare in low and middle-income countries: 
Ogunkorode et al

Treatment resource allocation. Cancer 2008;113(8), 2269-2281

36. Adenipekun A, Onibokun A, Elumelu TN and Soyannwo OA. Knowledge and attitudes of terminally ill patients and their family to palliative care and hospice services in Nigeria. Nigerian Journal of Clinical Practice 2005; 8(1), 19-22.

37. Bosnjak S, Maurer MA and Ryan KM. Improving the availability and accessibility of opioids for the treatment of pain. The International Pain Policy Fellowship. Support Care Cancer 2011; 19, 12391247.

38. World Health Assembly. $58^{\text {th }}$ World health Assembly 58.22. Resolution and detection-Cancer prevention and controls. WHA58.22. Geneva, Switzerland: World Health Organization. Retrieved from
Breast Cancer Early Detection and Care

http://apps.who.int./gp/ebwhal/pdf_files/WHA58/ WHA58_22-en.pdf 2005

39. Coughlin SS and Ekwueme DU. Breast cancer as a global health concern. Cancer Epidemiology 2009; 33, 315-318.

40. Adisa AO, Lawal OO and Adesunkanmi AK. Breast cancer in Nigeria: Is non-adherence to chemotherapy schedules a major factor in the reported poor treatment outcome? The Breast Journal 2010; 16(2),206-207. doi10.1111/j.15244741.2009. 00883. x

41. Smith LK, Pope C and Botha JL. Patient's help-seeking experiences and delay in cancer presentations: A qualitative synthesis. The Lancet 2005; 366, 825831.doi:10.1016/S0140-6736(5)67030-4. 